\title{
Predictive power of splenic thickness for post-hepatectomy liver failure in HBV- associated hepatocellular carcinoma patients
}

\author{
Xiang Chen, Heng Zou, Li Xiong, Sheng-Fu Huang, Xiong-Ying Miao and Yu Wen * (D)
}

\begin{abstract}
Background: The purpose of this case series is to investigate the relationship between splenic thickness (ST) and postoperative outcomes after hepatic resection in hepatitis B virus (HBV)-associated hepatocellular carcinoma (HCC) patients.

Methods: The clinical data of 320 patients with HBV-associated HCC who had undergone liver resection were retrospectively analyzed. The value of ST in predicting postoperative outcomes was evaluated.

Results: A total of 320 patients were enrolled in the study. An increase in ST was significantly associated with an increase in portal vein diameter (PVD), indocyanine green retention rate 15 min (ICG R15), and total bilirubin (TBIL); however, it was negatively correlated with platelet count (PLT). Post-hepatectomy liver failure (PHLF) occurred in 35 (10.9\%) patients. Multivariate logistic regression analysis showed that ST was an independent predictor of morbidity and mortality after hepatectomy. Meanwhile, ST was associated with an almost sixfold increased risk for developing perioperative complications (OR 5.678; 95\% Cl 2.873 to $11.224 ; P<0.001$ ) and almost 13-fold increased risk for mortality after hepatectomy (OR 13.007; 95\% Cl 1.238 to 136.627; $P=0.033$ ). The area under the receiver operating characteristic (ROC) curve (AUC) of ST for predicting the incidence of PHLF was 0.754 (95\% confidence interval (Cl) 0.667 to 0.841 ; $P<0.001$ ), with a sensitivity of $57.1 \%$ and a specificity of $82.5 \%$, which were significantly greater than those of the ICG R15 level (AUC 0.670; 95\% Cl 0.560 to 0.779; $P<0.001$ ). The critical value of ST was $43.5 \mathrm{~mm}$.
\end{abstract}

Conclusions: ST, which is an easy, inexpensive, and routinely available perioperative marker, showed a favorable predictive value for postoperative outcomes in HBV-associated HCC patients.

Keywords: Splenic thickness, Post-hepatectomy liver failure, Hepatitis B virus, Hepatocellular carcinoma, Mortality, Morbidity

\section{Background}

Hepatocellular carcinoma (HCC) is the second leading cause of cancer mortality worldwide and the sixth most common type of cancer [1]. Liver resection is an accepted first-line curative treatment and is performed in most HCC patients. Although recent advances in diagnosis, surgical techniques, and perioperative

\footnotetext{
* Correspondence: wenyu2861@csu.edu.cn

Xiang Chen and Heng Zou are the co-first authors.

Xiang Chen and Heng Zou contributed equally to this work.

Department of General Surgery, The Second Xiangya Hospital, Central South University, Renmin Road 139, Changsha 410011, Hunan, People's Republic of China
}

treatments have positively improved the safety and outcomes of hepatic surgery [2], post-hepatectomy liver failure (PHLF) still occasionally occurs in clinical practice and remains the major cause of hepatectomy-related mortality [3]. The risk for PHLF is high in patients with chronic liver disease or cirrhosis, especially in those patients who have portal hypertension or thrombocytopenia $[4,5]$. Hence, accurately assessing the safety of surgery prior to hepatectomy in these patients imperative.

The prevalence of histologic cirrhosis is high among patients with hepatitis B virus (HBV) and hepatitis C 
virus (HCV) infections [6]. In Asia, approximately 80\% of $\mathrm{HCC}$ cases occur in patients with cirrhosis derived from chronic HBV infection [7].These co-morbidities, along with portal hypertension [8], are associated with increased morbidity or mortality because of a significant impairment in liver function [9]. In addition, a palpable or enlarged spleen is common in these patients and is considered as an independent predictor of the presence of large esophageal varices, which carry a high risk of bleeding and allow the clinical progression of cirrhosis to be monitored [10]. Moreover, the liver-to-spleen ratio has been used to evaluate the severity of liver disease and predict post-hepatectomy complications [11]. Therefore, there is a need for preoperative spleen assessment during hepatic resection in HBV-associated HCC patients. This has resulted in the adoption of spleen size as a marker of the safety and prognosis of liver surgery [12-14].

However, using spleen size in the context of hepatectomy in HBV-associated HCC patients has not yet been investigated. Therefore, the present study assessed the use of the splenic thickness (ST) compared with the indocyanine green retention rate 15 min (ICG R15) level to predict PHLF and other postoperative outcomes in HBV-associated HCC patients undergoing hepatic resection.

\section{Methods}

\section{Patients}

Between November 2013 and January 2017, 366 patients underwent curative hepatic resection for $\mathrm{HCC}$ at the Second Xiangya Hospital of Central South University. The inclusion criteria for this study were as follows: good liver functional reserve with Child-Pugh $(\mathrm{CP})$ grade $\mathrm{A}$ or $\mathrm{B}$, no treatment for $\mathrm{HCC}$ before liver resection, positivity of hepatitis B surface antigen $(\mathrm{HBsAg})$, and no cardiopulmonary, renal, or cerebral dysfunction before liver resection. The exclusion criteria were as follows: co-infection with $\mathrm{HCV}$ and/or human immunodeficiency virus, previous splenectomy, and any other known cause of splenomegaly (i.e., hematopathy, infections, inflammatory, or primary splenic diseases). Finally, a total of 320 patients were included in this study. The patients were stratified into the normal spleen group (ST $<40 \mathrm{~mm}$ ) or the thickened spleen group (ST $\geq 40 \mathrm{~mm}$ ).

All patients gave their informed consent to participate in the clinical study, and approvals were obtained from the ethics committee at Central South University.

\section{Perioperative management}

Routine preoperative investigations were performed on all patients and included a thorough history, physical examination, routine blood tests, chest X-ray, ultrasonography, and contrast-enhanced computed tomography
(CT) or magnetic resonance imaging (MRI) of the abdomen. A preoperative ICG clearance test and CT volumetry were undertaken routinely to evaluate the functional reserve of the future liver remnant. Anti-HBV treatment was administered to the patients following surgery as needed. Postoperative laboratory tests included routine blood tests, biochemical tests, and coagulation function tests and were performed on the first, third, fifth, and seventh days after surgery or thereafter as needed. Ultrasonography was performed on the fifth day after the surgery to detect whether there was pleural fluid or abdominal ascites.

\section{Definitions}

Splenic thickness was measured by ultrasound and defined as the transversal distance between the porta lienis and the point of tangency of the lateral border, which was examined by a senior radiologist who had extensive experience in sonography. Two or three measurements were averaged when the thickness of the anterior and posterior portions of the spleen differed considerably. All patients were imaged while resting in a supine position with an empty stomach. The ultrasonographic measurement of splenic thickness was technically feasible in all patients.

Liver resection was classified as minor hepatectomy (segmentectomy and non-anatomic wedge resection of two segments or fewer) and major hepatectomy (three Couinaud segments or more) [15]. Liver cirrhosis and HCC were diagnosed by the pathological examination of the resected specimen. Clinically significant portal hypertension $(\mathrm{CSPH})$ was defined by the presence of esophageal/gastric varices, splenomegaly (diameter greater than $12 \mathrm{~cm}$ on ultrasonography), or in patients with a low platelet count (PLT) $\left(<100 \times 10^{9} / \mathrm{l}\right)$ [16]. The presence of esophageal varices $(\mathrm{EV})$ was demonstrated by upper digestive endoscopy on all patients. PHLF was defined as a total serum bilirubin value $>50 \mu \mathrm{mol} / \mathrm{l}$ and a prothrombin time index $<50 \%$ (equal to an international normalized ratio (INR) $>1.7$ ) on postoperative day 5 or thereafter, based on the International Study Group of Liver Surgery (ISGLS) classification [17, 18]. The model for end-stage liver disease (MELD) score was calculated using the following formula: $11.2 \times \ln$ (international normalized ratio $)+9.57 \times \ln ($ creatinine, $\mathrm{mg} / \mathrm{dl})$ $+3.78 \times \ln$ (bilirubin, $\mathrm{mg} / \mathrm{dl})+6.43 \times($ etiology -0 if cholestatic or alcoholic, 1 otherwise) [19]. Postoperative complications were classified according to the DindoClavien classification during the 30 days after hepatectomy [20].A major complication was defined as grade 3 or above and a grade 2 or less qualified as a minor complication. Mortality was defined as death occurring during the 30 days after liver resection. 


\section{Statistical methods}

Statistical analyses were performed using SPSS 17.0 (SPSS, Inc., Chicago, IL, USA). Categorical variables were presented as relative frequencies and percentages and were compared using the $\chi 2$ test or Fisher's exact test. Continuous variables were expressed as the means \pm standard deviation (SD) and were compared using the Mann-Whitney $U$ test or Student's test as appropriate. A statistically significant result was defined as $P<0.05$, and the $P$ values were two-sided. Univariate analysis and multivariate logistic regression analysis were performed to identify independent predictors for the development of PHLF and postoperative morbidity and mortality, and the adjusted odds ratio (OR) per standard deviation change and the $95 \%$ confidence interval (CI) were calculated. The predictive ability of ST and ICG R15 was assessed by the receiver operating characteristic (ROC) curve and the corresponding area under the ROC curve (AUC). The correlations between ST and other variables were tested by Spearman's rank correlation coefficients.

\section{Results}

\section{Characteristics of the patients}

Demographic and clinical characteristics of 320 patients were presented in Table 1. A total of 285 (89.1\%) men and $35(10.9 \%)$ women had a median age of 51 years (range 17-77), and the median splenic thickness value of the entire study cohort was $37.5 \mathrm{~mm}$ (range 19-72). Among these 320 patients, 228 patients $(71.2 \%)$ were diagnosed with liver cirrhosis after hepatectomy. According to the $\mathrm{CP}$ grade, the majority of patients had grade A (289/320, 90.3\%), and the remaining patients had grade B. Based on the Dindo-Clavien classification, $68(21.2 \%)$ patients developed complications, and 43 (13.4\%) patients and $25(7.8 \%)$ patients were classified as having minor and major complications, respectively.

\section{Patient characteristics and operative details between the normal spleen group and thickened spleen group}

In our cohort, 97 (30.3\%) patients had a thickened spleen (ST $\geq 40 \mathrm{~mm}$ ) (shown in Table 1), with a median ST value of $49.3 \mathrm{~mm}$. Additionally, these patients had a significantly low preoperative PLT, long prothrombin time (PT), and increased INR. Patients in the thickened spleen group also had a significantly increased presence rate of cirrhosis ( 90.7 vs. $62.8 \%, P<0.001)$ and esophageal varices $(28.9$ vs. $5.4 \%, P<0.001)$, accompanied by a greater proportion of CP grade $\mathrm{B}(15.5$ vs. $7.2 \%, P=0.021)$ and higher MELD scores $(22.7$ vs. $9.0 \%, P=0.001)$, compared with the normal spleen group. In this context, although fewer patients in the thickened spleen group experienced a major liver resection, they developed more major and minor complications than did the normal group.
Table 1 Characteristics of patients with normal or thickened spleen

\begin{tabular}{|c|c|c|c|c|}
\hline Variables & $\begin{array}{l}\text { No. of patients } \\
(n=320)\end{array}$ & $\begin{array}{l}\text { Normal } \\
(n=223)\end{array}$ & $\begin{array}{l}\text { Thickening } \\
(n=97)\end{array}$ & $P$ \\
\hline Age, years & $51.4 \pm 10.6$ & $51.3 \pm 10.9$ & $51.7 \pm 9.7$ & 0.754 \\
\hline Gender & & & & 0.531 \\
\hline Male & 285 (89.1\%) & 197 (88.3\%) & 88 (90.7\%) & \\
\hline Female & 35 (10.9\%) & $26(11.7 \%)$ & $9(9.3 \%)$ & \\
\hline $\mathrm{BMI}, \mathrm{Kg} / \mathrm{m}^{2}$ & $22.6 \pm 3.2$ & $22.5 \pm 3.1$ & $22.8 \pm 3.3$ & 0.436 \\
\hline $\mathrm{PLT}, \times 10^{9} / \mathrm{I}$ & $156.7 \pm 79.7$ & $177.9 \pm 76.1$ & $107.7 \pm 65.3$ & $<0.001$ \\
\hline $\mathrm{ALT}, \mathrm{U} / \mathrm{I}$ & $42.8 \pm 32.8$ & $41.2 \pm 26.7$ & $46.5 \pm 43.6$ & 0.267 \\
\hline AST, U/I & $45.5 \pm 24.2$ & $44.9 \pm 21.8$ & $46.6 \pm 28.9$ & 0.575 \\
\hline$A L B, g / l$ & $38.2 \pm 4.2$ & $38.3 \pm 4.0$ & $38.1 \pm 4.8$ & 0.596 \\
\hline PT, s & $13.1 \pm 1.2$ & $12.9 \pm 1.2$ & $13.5 \pm 1.3$ & $<0.001$ \\
\hline INR & $1.1 \pm 0.1$ & $1.0 \pm 0.1$ & $1.1 \pm 0.1$ & $<0.001$ \\
\hline CREA, umol/l & $73.9 \pm 12.1$ & $74.1 \pm 12.1$ & $73.8 \pm 12.1$ & 0.744 \\
\hline TBIL, umol// & $15.1 \pm 7.2$ & $13.9 \pm 6.3$ & $17.7 \pm 8.5$ & $<0.001$ \\
\hline Tumor size, cm & $6.2 \pm 3.2$ & $6.4 \pm 3.2$ & $5.8 \pm 3.2$ & 0.131 \\
\hline $\begin{array}{l}\text { Operation time, } \\
\text { min }\end{array}$ & $188.7 \pm 59.8$ & $187.8 \pm 58.9$ & $190.8 \pm 62.1$ & 0.684 \\
\hline ICG R15, \% & $7.4 \pm 4.4$ & $6.7 \pm 3.3$ & $9.2 \pm 6.0$ & $<0.001$ \\
\hline $\mathrm{ST}, \mathrm{mm}$ & $37.5 \pm 9.2$ & $32.4 \pm 3.0$ & $49.3 \pm 7.7$ & $<0.001$ \\
\hline Blood loss, ml & $593.2 \pm 702.1$ & $\begin{array}{l}563.7 \pm \\
721.5\end{array}$ & $\begin{array}{l}661.0 \pm \\
653.9\end{array}$ & 0.255 \\
\hline PVD, mm & $11.0 \pm 1.9$ & $10.5 \pm 1.5$ & $12.3 \pm 2.3$ & $<0.001$ \\
\hline PVT & & & & 0.958 \\
\hline Positive & $50(15.6 \%)$ & 35 (15.7\%) & 15 (15.5\%) & \\
\hline Negative & 270 (84.4\%) & $188(84.3 \%)$ & $82(84.5 \%)$ & \\
\hline EV & & & & $<0.001$ \\
\hline Positive & $40(12.5 \%)$ & $12(5.4 \%)$ & 28 (28.9\%) & \\
\hline Negative & $280(87.5 \%)$ & $211(94.6 \%)$ & 69 (71.1\%) & \\
\hline $\mathrm{CSPH}$ & & & & $<0.001$ \\
\hline Positive & $88(27.5 \%)$ & $23(10.3 \%)$ & $65(67.0 \%)$ & \\
\hline Negative & 232 (72.5\%) & $200(89.7 \%)$ & $32(33.0 \%)$ & \\
\hline Cirrhosis & & & & $<0.001$ \\
\hline Positive & $228(71.2 \%)$ & $140(62.8 \%)$ & 88 (90.7\%) & \\
\hline Negative & 92 (28.8\%) & $83(37.2 \%)$ & $9(9.3 \%)$ & \\
\hline Liver resection & & & & 0.126 \\
\hline Minor & 261 (81.6\%) & 177 (79.4\%) & 84 (86.6\%) & \\
\hline Major & $59(18.4 \%)$ & $46(20.6 \%)$ & $13(13.4 \%)$ & \\
\hline Complication & & & & $<0.001$ \\
\hline None & 252 (78.8\%) & 203 (91.0\%) & $49(50.5 \%)$ & \\
\hline Minor & $43(13.4 \%)$ & $11(4.9 \%)$ & $32(33.0 \%)$ & \\
\hline Major & 25 (7.8\%) & $9(4.0 \%)$ & $16(16.5 \%)$ & \\
\hline
\end{tabular}

d-Pugh grade 
Table 1 Characteristics of patients with normal or thickened spleen (Continued)

\begin{tabular}{lllll}
\hline Variables & $\begin{array}{l}\text { No. of patients } \\
(n=320)\end{array}$ & $\begin{array}{l}\text { Normal } \\
(n=223)\end{array}$ & $\begin{array}{l}\text { Thickening } \\
(n=97)\end{array}$ & $P$ \\
\hline B & $31(9.7 \%)$ & $16(7.2 \%)$ & $15(15.5 \%)$ & \\
& MELD & & & \\
$<7.5$ & $278(86.9 \%)$ & $203(91.0 \%)$ & $75(77.3 .0 \%)$ & 0.001 \\
$\geq 7.5$ & $42(13.1 \%)$ & $20(9.0 \%)$ & $22(22.7 \%)$ & \\
\hline
\end{tabular}

Abbreviation: BMI body mass index, PLT platelet counts, $A L T$ alanine transaminase, $A S T$ aspartate aminotransferase, $A L B$ albumin, $P T$ prothrombin time, INR international normalized ratio, CREA creatinine, TBIL total bilirubin, ST splenic thickness, PVD portal vein diameter, PVT portal vein thrombus, EV esophageal varices, CSPH clinically significant portal hypertension, ICG R15 indocyanine green retention rate $15 \mathrm{~min}, M E L D$ the model for end-stage liver disease

Data are expressed as means \pm SD or $n(\%)$

\section{Patient characteristics according to the development of PHLF}

A comparison of patient demographics and clinical variables in the PHLF group and non-PHLF group was presented in Table 2. PHLF occurred in 35 patients (10.9\%). A lower PLT and greater total bilirubin (TBIL) were associated with patients who developed PHLF. A thickened spleen was significantly associated with the development of PHLF. Moreover, the underlying impaired liver that was associated with the cirrhosis significantly affected the development of PHLF, which was consistent with the increased ICG R15 in the PHLF group. In addition, more patients who developed PHLF had CSPH than those without PHLF (54.3\% (19/35) vs. $24.2 \%(69 / 285), \quad P<0.001)$. Regarding the surgical factors, blood loss and the proportion of major liver resection were significantly greater in patients with PHLF, while the operation time was similar between the two groups.

\section{Univariate and multivariate analyses of post-hepatectomy liver failure}

To evaluate the independent predictive factors of PHLF during the perioperative period, we performed univariate and multivariate analyses to identify surgery-related and chronic liver disease-related variables (shown in Table 3). Univariate analysis showed that six variables were significantly associated with the development of PHLF, which included PLT, ST, TBIL, perioperative blood loss, major hepatic resection, and ICG R15. Multivariate logistic regression analysis indicated that ST, PLT, and major hepatic resection were identified as independent risk factors for predicting PHLF. It seems that ST (OR 3.39; 95\% CI 1.374 to $8.362 ; P=0.008)$ was a stronger independent risk predictor for PHLF than was ICG R15 (OR 2.130; $95 \%$ CI 0.893 to $5.081 ; P=0.088)$.
Table 2 Study population and clinicopathological characteristics according to the development of PHLF

\begin{tabular}{|c|c|c|c|}
\hline Variables & PHLF $(-)(n=285)$ & $\operatorname{PHLF}(+)(n=35)$ & $P$ \\
\hline Age, years & $51.2 \pm 10.5$ & $53.3 \pm 11.1$ & 0.255 \\
\hline $\mathrm{BMl}, \mathrm{Kg} / \mathrm{m} 2$ & $22.6 \pm 3.1$ & $22.3 \pm 3.4$ & 0.589 \\
\hline $\mathrm{PLT}, \times 10^{9} / \mathrm{l}$ & $161.7 \pm 80.2$ & $115.6 \pm 63.0$ & 0.001 \\
\hline $\mathrm{ALT}, \mathrm{U} / \mathrm{I}$ & $41.9 \pm 31.0$ & $50.3 \pm 44.2$ & 0.153 \\
\hline AST, U/I & $44.2 \pm 22.8$ & $55.5 \pm 31.8$ & 0.050 \\
\hline$A L B, g / l$ & $38.3 \pm 4.2$ & $37.2 \pm 4.8$ & 0.129 \\
\hline PT, s & $13.1 \pm 1.2$ & $13.1 \pm 1.3$ & 0.946 \\
\hline INR & $1.1 \pm 0.1$ & $1.0 \pm 0.1$ & 0.513 \\
\hline CREA, umol// & $74.6 \pm 11.9$ & $69.0 \pm 12.9$ & 0.010 \\
\hline TBIL, umol/I & $14.6 \pm 6.6$ & $19.0 \pm 10.7$ & 0.020 \\
\hline Tumor size, cm & $6.1 \pm 3.2$ & $7.3 \pm 3.4$ & 0.030 \\
\hline Operation time, min & $187.5 \pm 59.3$ & $198.5 \pm 63.8$ & 0.307 \\
\hline ICG R15, \% & $7.1 \pm 4.2$ & $9.7 \pm 5.4$ & 0.010 \\
\hline ST, mm & $36.5 \pm 8.4$ & $45.5 \pm 10.9$ & $<0.001$ \\
\hline Blood loss, ml & $526.6 \pm 502.5$ & $1135.7 \pm 1475.1$ & 0.021 \\
\hline PVD, mm & $11.0 \pm 2.0$ & $11.1 \pm 1.4$ & 0.800 \\
\hline PVT & & & 0.223 \\
\hline Positive & 47 (16.5\%) & $3(8.6 \%)$ & \\
\hline Negative & $238(83.5 \%)$ & 32 (91.4\%) & \\
\hline EV & & & 0.281 \\
\hline Positive & $38(13.3 \%)$ & $2(5.7 \%)$ & \\
\hline Negative & $247(86.7 \%)$ & 33 (94.3\%) & \\
\hline $\mathrm{CSPH}$ & & & $<0.001$ \\
\hline Positive & $69(24.2 \%)$ & $19(54.3 \%)$ & \\
\hline Negative & $216(75.8 \%)$ & $16(45.7 \%)$ & \\
\hline Cirrhosis & & & 0.108 \\
\hline Positive & $199(69.8 \%)$ & 29 (82.9\%) & \\
\hline Negative & 86 (30.2\%) & $6(17.1 \%)$ & \\
\hline Liver resection & & & 0.036 \\
\hline Minor & $237(83.2 \%)$ & 24 (68.6\%) & \\
\hline Major & 48 (16.8\%) & 11 (31.4\%) & \\
\hline Child-Pugh grade & & & 0.128 \\
\hline A & $260(91.2 \%)$ & 29 (82.9\%) & \\
\hline B & $25(8.8 \%)$ & $6(17.1 \%)$ & \\
\hline MELD & & & 0.193 \\
\hline$<7.5$ & $250(87.7 \%)$ & $28(80.0 \%)$ & \\
\hline$\geq 7.5$ & 35 (12.3\%) & 7 (20.0\%) & \\
\hline
\end{tabular}

Abbreviation: $P H L F$ post-hepatectomy liver failure, $B M I$ body mass index, $P L T$ platelet counts, $A L T$ alanine transaminase, AST aspartate aminotransferase, $A L B$ albumin, $P T$ prothrombin time, INR international normalized ratio, CREA creatinine, TBIL total bilirubin, ST splenic thickness, PVD portal vein diameter, $P V T$ portal vein thrombus, EV esophageal varices, CSPH clinically significant portal hypertension, ICG $R 15$ indocyanine green retention rate $15 \mathrm{~min}$, MELD the model for end-stage liver disease

Data are expressed as means \pm SD or $n(\%)$ 
Table 3 Univariable and multivariable analyses to identify predictors of PHLF in HBV-associated HCC patients

\begin{tabular}{|c|c|c|c|c|}
\hline \multirow[t]{2}{*}{ Variables } & \multicolumn{2}{|l|}{ Univariate analysis } & \multicolumn{2}{|l|}{ Multivariate analysis } \\
\hline & Odds ratio & $P$ & Odds ratio & $P$ \\
\hline Age, years & $1.587(0.749,3.364)$ & 0.228 & $1.372(0.587,3.206)$ & 0.465 \\
\hline $\mathrm{BMl}, \mathrm{Kg} / \mathrm{m} 2$ & $0.886(0.429,1.831)$ & 0.744 & $0.738(0.323,1.688)$ & 0.472 \\
\hline Platelet count, $\times 10^{9} / \mathrm{I}$ & $4.549(2.205,9.384)$ & $<0.001$ & $2.608(1.047,6.497)$ & 0.040 \\
\hline Operation time, $\min$ & $0.878(0.429,1.796)$ & 0.722 & $0.768(0.339,1.743)$ & 0.529 \\
\hline $\mathrm{ST}, \mathrm{mm}$ & $5.465(2.591,11.529)$ & $<0.001$ & $3.390(1.374,8.362)$ & 0.008 \\
\hline Prothrombin time, s & $1.408(0.689,2.879)$ & 0.348 & $0.869(0.382,1.980)$ & 0.739 \\
\hline TBIL, umol/I & $2.981(1.381,6.435)$ & 0.005 & $1.975(0.816,4.778)$ & 0.131 \\
\hline Blood loss, ml & $2.389(1.081,5.280)$ & 0.031 & $1.655(0.672,4.074)$ & 0.273 \\
\hline Major hepatic resection & $2.263(1.039,4.928)$ & 0.040 & $4.280(1.624,11.282)$ & 0.003 \\
\hline ICG R15, \% & $4.119(1.981,8.561)$ & $<0.001$ & $2.130(0.893,5.081)$ & 0.088 \\
\hline
\end{tabular}

PHLF post-hepatectomy liver failure, HCC hepatocellular carcinoma, BMI body mass index, ST splenic thickness, TBIL total bilirubin, ICG R15 indocyanine green retention rate $15 \mathrm{~min}$

Data in parentheses are $95 \% \mathrm{Cl}$

\section{Discriminatory power of ST and ICG R15 for post-hepatectomy liver failure}

The area under the ROC curve of the ST (AUC 0.754; 95\% CI 0.667 to $0.841 ; P<0.001$ ) for predicting PHLF was greater than that of the ICG R15 (AUC 0.670; 95\% CI 0.560 to $0.779 ; P<0.001$ ) (shown in Fig. 1 ). The optimal cut-off value of ST was $43.5 \mathrm{~mm}$, with a sensitivity of $57.1 \%$ and a specificity of $82.5 \%$ for predicting PHLF. Regarding the critical value of ST and ICG R15 (shown in Table 4), patients with a ST of $43.5 \mathrm{~mm}$ or above had a higher incidence of PHLF than patients with ST less than $43.5 \mathrm{~mm}, 20(28.6 \%)$ of 70 patients and $15(6 \%)$ of 250 patients, respectively, (OR 6.267; $P<0.001$ ). Although there was a significant difference in the incidence of PHLF between patients with higher ICG R15 levels $(\geq 7.95 \%)$ and those with lower ICG R15 levels (< 7.95\%) (OR 4.665;

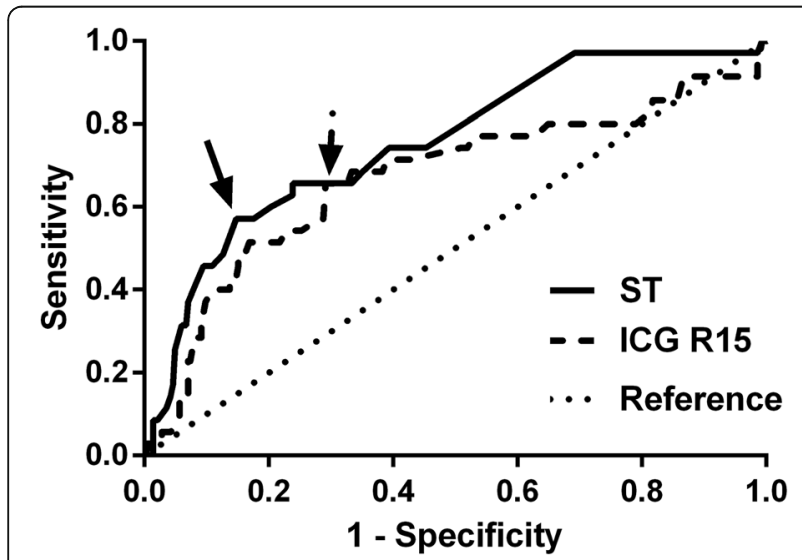

Fig. 1 Receiver operating characteristic (ROC) curves of splenic thickness (ST) and indocyanine green retention rate 15 min (ICG R15) for predicting post-hepatectomy liver failure with HCC patients. Arrows show optimal cut-off values for ST $43.5 \mathrm{~mm}$ (sensitivity of 57.1\%, specificity of $82.5 \%$ ) and ICG R15 7.95 (sensitivity of $65.7 \%$, specificity of 70.9\%). Area under the curve 0.754 for ST versus 0.670 for ICG R15
$P<0.001)$, the results suggested that the predictive value of ST was better than that of ICG R15.

\section{Correlation between ST and other preoperative variables}

Spearman's rank correlation analysis was used to analyze the correlation between ST and PLT, TBIL, portal vein diameter (PVD), and ICG R15. ST was positively correlated with TBIL, ICG R15, and PVD and negatively correlated with PLT. As shown in Fig. 2, although correlations with these four variables achieved statistical significance, ST was strongly correlated with preoperative PLT $(r-0.433 ; P<0.001)$ and PVD $(r$ 0.487; $P<0.001)$ and weakly correlated with ICG R15 $(r 0.202 ; P<0.001)$.

\section{Postoperative morbidity and mortality}

To further assess the independent predictive risk value of ST in the early postoperative period, we performed multivariate logistic regression analyses to recognize clinicopathologic variables associated with perioperative morbidity and mortality (Table 5). ST was associated with an almost sixfold increased risk for developing

Table 4 The chi-square test in $2 \times 2$ table for the cut-off value of PHLF

\begin{tabular}{lllll}
\hline Variables & $\begin{array}{l}\text { PHLF }(-) \\
(n=285)\end{array}$ & $\begin{array}{l}\text { PHLF }(+) \\
(n=35)\end{array}$ & Odds ratio & $P$ \\
\hline Splenic thickness & & & 6.267 & $<0.001$ \\
ST $<43.5 \mathrm{~mm}(n)$ & $235(82.5 \%)$ & $15(42.9 \%)$ & & \\
ST $\geq 43.5 \mathrm{~mm}(n)$ & $50(17.5 \%)$ & $20(57.1 \%)$ & & \\
ICG R15 & & & 4.665 & $<0.001$ \\
ICG R15 $<7.95 \%(n)$ & $202(70.9 \%)$ & $12(34.3 \%)$ & & \\
ICG R15 $\geq 7.95 \%(n)$ & $83(29.1 \%)$ & $23(65.7 \%)$ & & \\
\hline
\end{tabular}

PHLF post-hepatectomy liver failure, ST splenic thickness, ICG R15 indocyanine green retention rate $15 \mathrm{~min}$ 

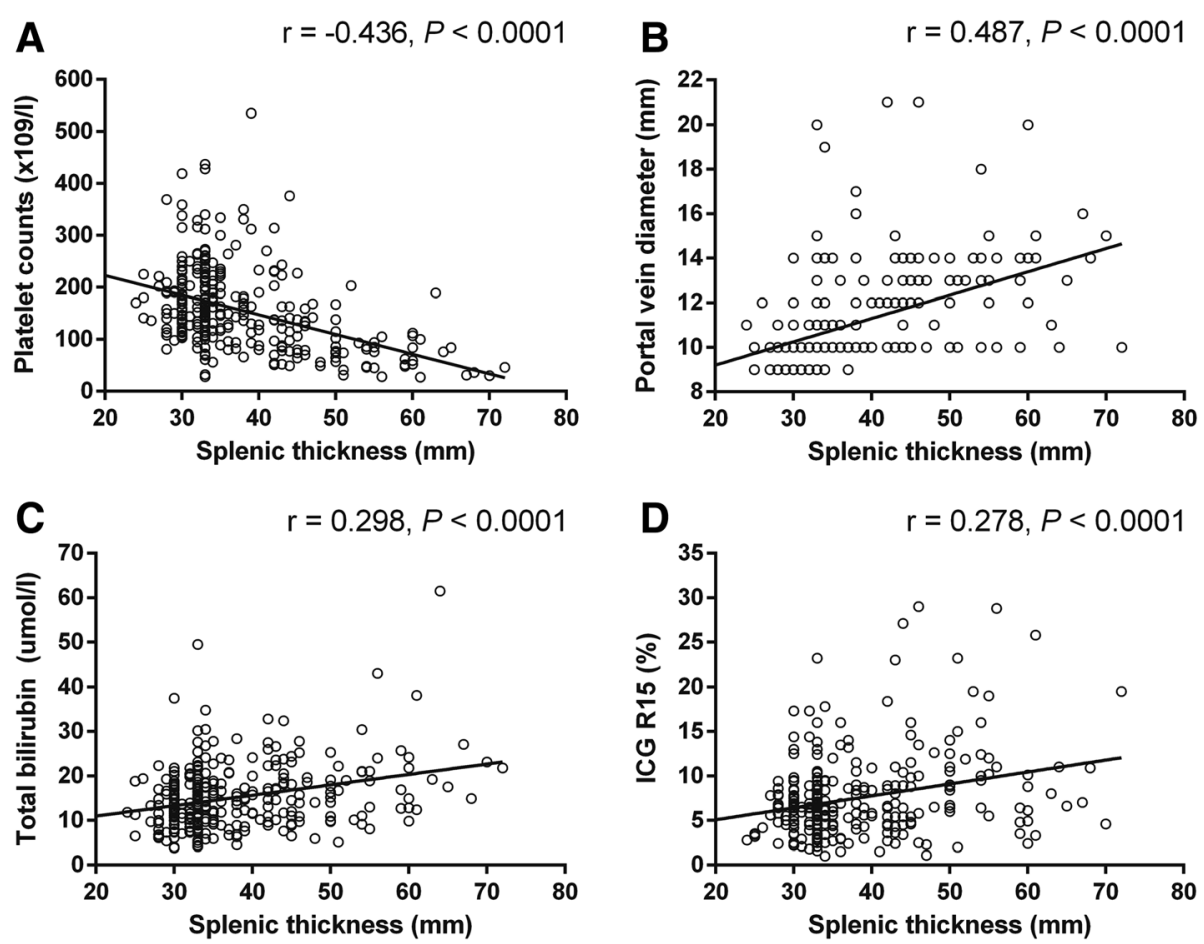

Fig. 2 Scatterplots show correlations between splenic thickness (ST) and a platelet counts (PLT), b portal vein diameter (PVD), c total bilirubin (TBIL), and d ICG R15

perioperative complications after hepatectomy (OR 5.678; $95 \%$ CI 2.873 to11.224; $P<0.001)$. Of the entire cohort, seven patients $(2.19 \%)$ died within 30 days of hepatectomy. Four patients died because of PHLF followed by multiple organ failure and sepsis, and three patients died before POD 3 because of multiple organ failure following massive hemorrhage. Mortality within 30 days after liver resection was almost 13-fold higher in patients with a thickened spleen (OR 13.007; 95\% CI 1.238 to $136.627 ; P=0.033)$. In addition, the results suggested that ICG R15 was statistically insignificant in predicting both morbidity and mortality.

\section{Discussion}

Given that there is a high mortality associated with PHLF, there is an increased interest in identifying HCC patients who are at risk for hepatic dysfunction or failure at the preoperative stage. An effective tool to achieve this target is volumetric analysis using CT scans. Nevertheless, PHLF remains a severe complication of hepatic resection, which occurs in approximately $8 \%$ of the patients undergoing major hepatectomy. Thus, early recognition and therapy are crucial to enhance the survival of patients in the setting of PHLF. The observation of preoperative splenomegaly and hypersplenism in patients with liver cirrhosis or chronic hepatitis prompted an investigation into whether splenic thickness is a predictor of hepatic resection. In the present study, we demonstrated for the first time that ST was associated with morbidity, PHLF, and mortality after hepatectomy, particularly in patients with $\mathrm{ST} \geq 43.5 \mathrm{~mm}$, where hepatic resection resulted in a significantly higher proportion of PHLF. Meanwhile, ST may be superior

Table 5 Possible risk factors associated with postoperative morbidity and mortality

\begin{tabular}{|c|c|c|c|c|c|c|}
\hline \multirow[t]{2}{*}{ Variables } & \multicolumn{3}{|l|}{ Morbidity } & \multicolumn{3}{|l|}{ Mortality } \\
\hline & Odds ratio & $95 \% \mathrm{Cl}$ & $P$ & Odds ratio & $95 \% \mathrm{Cl}$ & $P$ \\
\hline Platelet count, $\times 10^{9} / \mathrm{I}$ & 3.691 & $1.739-7.832$ & 0.001 & 1.004 & $0.127-7.947$ & 0.997 \\
\hline Tumor size, $\mathrm{cm}$ & 1.639 & $0.810-3.319$ & 0.170 & 0.053 & $0.004-0.699$ & 0.026 \\
\hline Splenic thickness, mm & 5.678 & $2.873-11.224$ & $<0.001$ & 13.007 & $1.238-136.627$ & 0.033 \\
\hline Major hepatic resection & 1.217 & $0.528-2.808$ & 0.645 & 17.806 & $2.043-155.189$ & 0.009 \\
\hline ICG R15, \% & 1.437 & $0.750-2.746$ & 0.272 & 2.448 & $0.375-15.975$ & 0.350 \\
\hline
\end{tabular}

ICG R15 indocyanine green retention rate $15 \mathrm{~min}$ 
to the ICG R15 level in predicting the development of PHLF in HBV-associated HCC patients.

The spleen, though as a secondary peripheral lymphoid organ in the human body, has been considered unnecessary for life so far. Nevertheless, the spleen serves extremely significant immunological and hematological functions and is closely related to the liver [21]. Owing to the spleen is anatomically linked to the liver via the portal vein system; once the histology and hemodynamics of hepatic had changed, so did the spleen. Many previous studies have introduced spleen size as a diagnostic criterion for cirrhosis [22].The former finding of Chen $\mathrm{X}$ et al. [23] in a cohort of hepatitis B cirrhosis patients showed the spleen volume and spleen multidimensional index increased with increasing Child-Pugh class of cirrhosis. Tsushima et al. [24] reported that the spleen longitudinal diameter in patients with a non-alcoholic fatty liver disease was significantly higher than in healthy subjects. In addition, Murata $\mathrm{Y}$ et al. [25] showed that patients with primary biliary cirrhosis $(\mathrm{PBC})$ tended to have a larger spleen, especially in $\mathrm{PBC}$ patients who developed symptoms. However, some reports indicated that the spleen size in patients with alcoholic cirrhosis was smaller than in those with hepatitis $\mathrm{C}$ and non-alcoholic steatohepatitis cirrhosis [22, 26].

Child-Pugh grade and MELD scores have been widely used to predict the risk of death and complications in patients with liver diseases, sometimes been considered as a further aspect of the liver cirrhosis severity [27]. In our results, the patients with thickened spleen have a higher proportion of CP-B than normal group (15.5 vs. $7.2 \%$, respectively), so does MELD (22.7 vs. 9.0\%, respectively). And with increasing thickness of the spleen, the patients get higher MELD scores. This was in accordance with the recent study reported by Haliloglu $\mathrm{N}$ [28]. Meanwhile, a thicker spleen seems to more likely to be in the context of cirrhosis in our present study. It can be said that the thicker the spleen is the more possibility to give results by abnormal liver in histology and function.

Among the various qualitative tests for liver function, ICG R15 has long been considered as one of the most powerful predictors of post-hepatectomy mortality [29]. However, ICG R15 may be an inaccurate predictor under certain conditions, such as in patients with jaundice or heart failure. The value of splenic thickness in predicting PHLF was comparable to that of the ICG R15 level. According to the ROC curve analysis for predicting PHLF, the AUC for ST and ICG R15 level was 0.754 and 0.670 , respectively, which suggested that $\mathrm{ST}$ is a superior predictor of PHLF compared with the ICG R15 level. Although the sensitivity of ST was $57.1 \%$ and relatively lower than the $65.7 \%$ for the sensitivity of the ICG R15 level, a higher specificity of ST may help the surgeon develop a better treatment plan, resulting in patients receiving treatment who would otherwise not be considered suitable for surgery based on the assessment of ICG R15. Moreover, the present study showed that ST was associated with morbidity and mortality after liver resection in HCC patients, which was not the case with the ICG R15 level. Thus, it can be concluded that ST was a better predictor of PHLF and other post-hepatectomy outcomes than the ICG R15 level. Postoperative complications, such as bleeding, abdominal infection, ascites, and liver dysfunction, will inevitably prolong the hospital stay, increase the cost of treatment, and even lead to death. Therefore, surgical procedures involving liver resection in patients with $\mathrm{ST} \geq 43.5 \mathrm{~mm}$ should be given critically important perioperative consideration.

In general, patients with a greater degree of cirrhosis have a higher portal venous pressure (PVP). Recently, $\mathrm{CSPH}$, as a surrogate measure of PVP, has been demonstrated to have the ability to predict the incidence of PHLF [16]. Our study showed that CSPH is a risk factor for hepatectomy because the incidence of CSPH in patients with PHLF was 54.3\% (19/35) versus $24.2 \%$ (69/ 285 ) in patients without PHLF. Indeed, $82.9 \%$ of the patients with PHLF had liver cirrhosis compared with $69.8 \%$ of the patients without PHLF. Furthermore, the incidence of CSPH was statistically significantly higher in the thickened spleen group and was accompanied by high TBIL and a greater presence of cirrhosis. In clinical practices, splenomegaly is usually defined as a longitudinal diameter $>12 \mathrm{~cm}$ [30]. Prassopoulos $\mathrm{P}$ and colleagues indicated that splenic thickness had a strong correlation with splenomegaly [31]. Furthermore, splenomegaly was viewed as a surrogate marker of portal hypertension in a previous study [32]. In our study, in addition to splenomegaly, the clinical manifestations of portal hypertension included thickening of the portal veins and faster blood flow [33]. A previous study suggested that portal vein diameter was an independent risk factor for CSPH and variceal bleeding [34]. We found a positive correlation between ST and PVD, which indicates that patients with greater ST may have higher portal pressure, although the latter was not determined in this study.

A negative correlation between ST and PLT was found in this study, which was evident from the finding that a low platelet count was associated with greater ST. This negative correlation in our study is in agreement with the thrombocytopenia and splenomegaly that arise due to the sequestration and destruction of platelets in liver cirrhosis [6]. Several clinical studies have indicated that preoperative thrombocytopenia is a risk factor associated with postoperative complications and mortality $[35,36]$. This was consistent with our result that preoperative PLT was significantly lower in the PHLF group than in 
the non-PHLF group. Furthermore, hypersplenism leading to thrombocytopenia, which is frequent in patients with cirrhosis due to portal hypertension [37], may be a reason for the ability of ST to predict PHLF.

This study has certain limitations. First, we enrolled only HBV-infected HCC patients from China, and therefore, the study may suffer selection bias. Other causes of HCC include HCV infection and alcoholism, both of which are prevalent mainly in Europe and North America [38] and may change the prediction value of splenic thickness in PHLF. Second, parameters such as spleen length, spleen width, or spleen index, which are indicative of splenomegaly, were not measured by $\mathrm{CT}$ in this study. Finally, because this study was a single-study site retrospective analysis of clinical data, future research will require a multicenter validation of our findings.

\section{Conclusions}

We demonstrated firstly that the thickness of the spleen is a strong predictor of the occurrence of PHLF in HBVassociated HCC patients undergoing hepatic resection. Furthermore, ST may be a better predictor of PHLF compared with ICG R15.

\section{Abbreviations \\ ALB: Albumin; ALT: Alanine transaminase; AST: Aspartate aminotransferase; AUC: Area under the receiver operating characteristic curve; BMI: Body mass index; Cl: Confidence interval; CP: Child-Pugh; CREA: Creatinine; CSPH: Clinically significant portal hypertension; $C \mathrm{CT}$ : Computed tomography; EV: Esophageal varices; HBsAg: Hepatitis B surface antigen; HBV: Hepatitis B virus; HCC: Hepatocellular carcinoma; HCV: Hepatitis C virus; ICG R15: Indocyanine green retention rate 15 min; INR: International normalized ratio; MELD: Model for end-stage liver disease; MRI: Magnetic resonance imaging; OR: Odds ratio; PBC: Primary biliary cirrhosis; PHLF: Post- hepatectomy liver failure; PLT: Platelet count; PT: Prothrombin time; PVD: Portal vein diameter; PVP: Portal venous pressure; PVT: Portal vein thrombus; ROC: Receiver operating characteristic; SD: Standard deviation; ST: Splenic thickness; TBIL: Total bilirubin}

\section{Acknowledgements}

Not applicable

\section{Funding}

The present study was supported by the National Nature Science Foundation of China (grant no. 81773293), the Key Research and Development Program of Hunan province (grant no. 2017DK2010), and the Big Date Project of Xiangya Medical School, Central South University.

\section{Availability of data and materials}

Please contact the authors for data requests.

\section{Authors' contributions}

$\mathrm{CX}$ and $\mathrm{ZH}$ performed the statistical analysis and wrote the manuscript. $\mathrm{XL}$, HSF, and MXY conceived the study concept, and participated in its design, and manuscript drafting. CX, ZH, and WY revised and edited the manuscript. All authors read and approved the final manuscript.

\section{Ethics approval and consent to participate}

Ethics approvals were obtained from the ethics committee at Central South University, and written consent of each patient was obtained.

\section{Consent for publication}

Written informed consent was obtained from the patients for publication of this case series. A copy of the written consent is available for review by the Editor-in-chief of this journal.

\section{Competing interests}

The authors declare that they have no competing interests.

\section{Publisher's Note}

Springer Nature remains neutral with regard to jurisdictional claims in published maps and institutional affiliations.

Received: 21 July 2017 Accepted: 20 November 2017

Published online: 04 December 2017

\section{References}

1. Torre LA, Bray F, Siegel RL, Ferlay J, Lortet-Tieulent J, Jemal A. Global cancer statistics, 2012. CA Cancer J Clin. 2015;65:87-108.

2. Poon RT, Fan ST, Lo CM, et al. Improving perioperative outcome expands the role of hepatectomy in management of benign and malignant hepatobiliary diseases: analysis of 1222 consecutive patients from a prospective database. Ann Surg. 2004;240:698-708. 708-10

3. Paugam-Burtz C, Janny S, Delefosse D, et al. Prospective validation of the "fifty-fifty" criteria as an early and accurate predictor of death after liver resection in intensive care unit patients. Ann Surg. 2009;249:124-8.

4. Cucchetti A, Ercolani G, Vivarelli M, et al. Is portal hypertension a contraindication to hepatic resection? Ann Surg. 2009;250:922-8.

5. Yang T, Zhang J, Lu JH, Yang GS, Wu MC, Yu WF. Risk factors influencing postoperative outcomes of major hepatic resection of hepatocellular carcinoma for patients with underlying liver diseases. World J Surg. 2011;35: 2073-82.

6. Yang JD, Kim WR, Coelho R, et al. Cirrhosis is present in most patients with hepatitis B and hepatocellular carcinoma. Clin Gastroenterol Hepatol. 2011;9:64.

7. Shariff MI, Cox IJ, Gomaa Al, Khan SA, Gedroyc W, Taylor-Robinson SD. Hepatocellular carcinoma: current trends in worldwide epidemiology, risk factors, diagnosis and therapeutics. Hepatic Med Evid Res. 2012;2012:19-37.

8. Bruix J, Sherman M. Management of hepatocellular carcinoma: an update. Hepatology. 2011:53:1020.

9. Jang $\mathrm{CW}$, Kwon HJ, Kong $\mathrm{H}$, et al. Impact of clinically significant portal hypertension on surgical outcomes for hepatocellular carcinoma in patients with compensated liver cirrhosis: a propensity score matching analysis. Ann Hepatobiliary Pancreat Surg. 2016;20:159-66.

10. Sharma SK, Aggarwal R. Prediction of large esophageal varices in patients with cirrhosis of the liver using clinical, laboratory and imaging parameters. J Gastroenterol Hepatol. 2007;22:1909-15.

11. Huang Y, Huang B, Kan T, Yang B, Yuan M, Wang J. Liver-to-spleen ratio as an index of chronic liver diseases and safety of hepatectomy: a pilot study. World J Surg. 2014;38:3186-92.

12. Arakawa $Y$, Shimada M, Utsunomiya T, et al. Gene profile in the spleen under massive partial hepatectomy using complementary DNA microarray and pathway analysis. J Gastroenterol Hepatol. 2014;29:1645-53.

13. Kim SJ, Na GH, Choi HJ, You Y, Kim DG. Effect of donor right hepatectomy on splenic volume and platelet count for living donor liver transplantation. J Gastrointest Surg. 2013;17:1576-83.

14. Zhang X, Li C, Wen T, et al. Synchronous splenectomy and hepatectomy for patients with small hepatocellular carcinoma and pathological spleen: neutrophil to lymphocyte ratio changes can predict the prognosis. Oncotarget. 2017:8:298-311.

15. Mullen JT, Ribero D, Reddy SK, et al. Hepatic insufficiency and mortality in 1,059 noncirrhotic patients undergoing major hepatectomy. J Am Coll Surgeons. 2007;204:854-62.

16. Chen X, Zhai J, Cai X, et al. Severity of portal hypertension and prediction of postoperative liver failure after liver resection in patients with Child-Pugh grade A cirrhosis. BRIT J SURG. 2012;99:1701-10.

17. Balzan S, Belghiti J, Farges O, et al. The "50-50 criteria" on postoperative day 5: an accurate predictor of liver failure and death after hepatectomy. Ann Surg. 2005;242:824-8. 828-9

18. Rahbari NN, Garden OJ, Padbury R, et al. Posthepatectomy liver failure: a definition and grading by the International Study Group of Liver Surgery (ISGLS). Surgery. 2011;149:713-24. 
19. Kamath PS, Kim WR. The model for end-stage liver disease (MELD). Hepatology. 2007:45:797-805.

20. Dindo D, Demartines N, Clavien PA. Classification of surgical complications: a new proposal with evaluation in a cohort of 6336 patients and results of a survey. Ann Surg. 2004;240:205-13.

21. Tarantino G, Scalera A, Finelli C. Liver-spleen axis: intersection between immunity, infections and metabolism. World J Gastroenterol. 2013;19:3534-42.

22. Kashani A, Salehi B, Anghesom D, Kawayeh AM, Rouse GA, Runyon BA. Spleen size in cirrhosis of different etiologies. J Ultrasound Med. 2015;34: 233-8.

23. Chen XL, Chen TW, Zhang XM, et al. Quantitative assessment of the presence and severity of cirrhosis in patients with hepatitis B using right liver lobe volume and spleen size measured at magnetic resonance imaging. PLoS One. 2014;9:e89973.

24. Tsushima Y, Endo K. Spleen enlargement in patients with nonalcoholic fatty liver: correlation between degree of fatty infiltration in liver and size of spleen. Dig Dis Sci. 2000;45:196-200.

25. Murata Y, Abe M, Hiasa Y, et al. Liver/spleen volume ratio as a predictor of prognosis in primary biliary cirrhosis. J Gastroenterol. 2008;43:632-6.

26. McCormick PA, Walker S, Benepal R. Hypersplenism is related to age of onset of liver disease. Ir J Med Sci. 2007;176:293-6.

27. Peng Y, Qi X, Tang S, et al. Child-Pugh, MELD, and ALBI scores for predicting the in-hospital mortality in cirrhotic patients with acute-on-chronic liver failure. Expert Rev Gastroenterol Hepatol. 2016;10:971-80.

28. Haliloglu N, Ozkavukcu E, Erden A. Are caudate-right lobe ratio and splenic size correlated with the MELD score in cirrhotic patients? Clin Imaging. 2013;37:526-9

29. Yokoyama $\mathrm{Y}$, Ebata $\mathrm{T}$, Igami $\mathrm{T}$, et al. The predictive value of indocyanine green clearance in future liver remnant for posthepatectomy liver failure following hepatectomy with extrahepatic bile duct resection. World I Surg. 2016;40:1440-7

30. Berzigotti A, Zappoli P, Magalotti D, Tiani C, Rossi V, Zoli M. Spleen enlargement on follow-up evaluation: a noninvasive predictor of complications of portal hypertension in cirrhosis. Clin Gastroenterol Hepatol. 2008;6:1129-34.

31. Prassopoulos P, Cavouras D. CT assessment of normal splenic size in children. Acta Radiol. 1994:35:152-4.

32. Boleslawski E, Petrovai $\mathrm{G}$, Truant $\mathrm{S}$, et al. Hepatic venous pressure gradient in the assessment of portal hypertension before liver resection in patients with cirrhosis. Br J Surg. 2012;99:855-63.

33. Sharma M, Rameshbabu CS. Collateral pathways in portal hypertension. J Clin Exp Hepatol. 2012;2:338-52.

34. Peñaloza-Posada MA, Pérez-Torres E, Pérez-Hernández JL, Tijera HDL. Noninvasive parameters as predictors of high risk of variceal bleeding in cirrhotic patients. Revista Medica Del Hospital General De Mexico. 2014;77:179-84.

35. Taketomi A, Kitagawa D, Itoh S, et al. Trends in morbidity and mortality after hepatic resection for hepatocellular carcinoma: an institute's experience with 625 patients. J Am Coll Surg. 2007;204:580-7.

36. Wang $H Q$, Yang J, Yang JY, Wang WT, Yan LN. Low immediate postoperative platelet count is associated with hepatic insufficiency after hepatectomy. World J Gastroenterol. 2014;20:11871-7.

37. Lisman T, Leebeek FW, de Groot PG. Haemostatic abnormalities in patients with liver disease. J Hepatol. 2002;37:280-7.

38. Fassio E. Hepatitis C and hepatocellular carcinoma. Ann Hepatol. 2010;9 Suppl:119-22.

\section{Submit your next manuscript to BioMed Central and we will help you at every step:}

- We accept pre-submission inquiries

- Our selector tool helps you to find the most relevant journal

- We provide round the clock customer support

- Convenient online submission

- Thorough peer review

- Inclusion in PubMed and all major indexing services

- Maximum visibility for your research

Submit your manuscript at www.biomedcentral.com/submit
Biomed Central 